OPEN ACCESS

Edited by:

Evandro L. de Souza,

Federal University of Paraíba, Brazil

Reviewed by:

Daniel Berdejo,

University of Zaragoza, Spain

Jossana Pereira Sousa Guedes, Federal University of Paraíba, Brazil

*Correspondence:

Jingyi Li

jingyileesd@126.com

Lei Shi

shilei_67@126.com

Specialty section:

This article was submitted to

Food Microbiology,

a section of the journal

Frontiers in Microbiology

Received: 15 July 2021 Accepted: 12 October 2021 Published: 05 November 2021

Citation:

Hao Y, Li J and Shi L (2021) A Carvacrol-Rich Essential Oil Extracted From Oregano (Origanum vulgare

"Hot \& Spicy") Exerts Potent

Antibacterial Effects Against

Staphylococcus aureus.

Front. Microbiol. 12:741861. do: 10.3389/fmicb.2021.741861

\section{A Carvacrol-Rich Essential Oil Extracted From Oregano (Origanum vulgare "Hot \& Spicy") Exerts Potent Antibacterial Effects Against Staphylococcus aureus}

\author{
Yuanpeng Hao ${ }^{1,2}$, Jingyi $\mathrm{Li}^{1 *}$ and Lei Shi ${ }^{1 *}$ \\ ${ }^{1}$ Key Laboratory of Plant Resources and Beijing Botanical Garden, Institute of Botany, Chinese Academy of Sciences, \\ Beijing, China, ${ }^{2}$ University of Chinese Academy of Sciences, Beijing, China
}

Oregano essential oil (OEO), as a natural antimicrobial, has gained increased interest from food researchers and manufacturers. However, a few studies have investigated its possible antibacterial effects against Staphylococcus aureus using the proteomic tool. The present study aimed to explore the antibacterial effect and mechanism of a carvacrol-rich OEO extracted from Origanum vulgare "Hot \& Spicy" on the inactivation of $S$. aureus. The gas chromatography-mass spectrometry analysis of the OEO allowed the detection of 27 compounds; the major constituent was carvacrol (84.38\% of total compounds). The average diameter of the inhibitory zone (DIZ) value was $29.10 \mathrm{~mm}$, and the minimum inhibitory concentration (MIC) and minimum bactericidal concentration (MBC) of OEO against $S$. aureus were 0.125 and $0.25 \mathrm{mg} / \mathrm{mL}$, respectively. The growth curve assay indicated that the OEO prolonged the lag phase of $S$. aureus. The decrease in cell viability, changes in the integrity of cell membrane, and abnormal cell morphology further reflected the cell damage of $S$. aureus caused by the OEO. In addition, a labelfree proteomic analysis was applied to analyze the regulatory networks of $S$. aureus in response to $1 / 2 \mathrm{MIC}$ OEO-treatment stress. Of the 56 differentially expressed proteins (DEPs) identified, 26 were significantly upregulated and 30 downregulated. The Kyoto Encyclopedia of Genes and Genomes pathway enrichment analysis indicated that the DEPs were mainly involved in pathways of ribosomes; valine, leucine, and isoleucine biosynthesis; and phenylalanine, tyrosine, and tryptophan biosynthesis, which suggested that the growth inhibition of $S$. aureus might be due to the disordered effect of the OEO on protein synthesis and amino acid metabolism. These findings deepened our understanding regarding $S$. aureus survival and metabolism responses to the OEO treatment and suggested that the carvacrol-rich OEO could be used in food production environments to effectively control $S$. aureus.

Keywords: carvacrol, cell membrane, oregano essential oil, proteomics, Staphylococcus aureus 


\section{INTRODUCTION}

Staphylococcus aureus is a facultative anaerobic Gram-positive foodborne pathogen involved in human outbreaks regarded as one of the world's leading causes of disease outbreaks related to food consumption (Jamali et al., 2015; Kang et al., 2019). S. aureus produces a wide variety of toxins, including staphylococcal enterotoxins, which commonly lead to staphylococcal food poisoning during the massive growth of $S$. aureus in various foods (Hait et al., 2021; Umeda et al., 2021). Moreover, S. aureus is ubiquitous and widely distributed in foods and food-processing environments, such as in raw meat and meat products as well as raw milk and dairy products (Wang et al., 2013; Titouche et al., 2019). The management of $S$. aureus poisoning has become increasingly difficult because of the emergence of multi-resistant strains caused by the widespread and often inappropriate use of antibiotics in livestock (Mehli et al., 2017; Zhang et al., 2020).

In the face of increasing $S$. aureus contamination, several emerging strategies for preventing and treating the contamination have been proposed, including the use of natural antimicrobial agents. Essential oils (EOs), aromatic and volatile secondary metabolites, have the potency to combat significant pathogens due to their broad-spectrum antimicrobial effects, which have been extensively evaluated in numerous food matrices, such as fruits, vegetables, meat, and milk products (Hyldgaard et al., 2012; Kang et al., 2018, 2019; Rao et al., 2019). EOs not only exert highly effective in inhibiting multidrugresistant bacteria (Lu et al., 2018; Cui et al., 2019) but also can greatly reduce the resistance of microbes through complex mixtures of natural compounds (Lu et al., 2018). Food-grade delivery systems, including microemulsions, nanoemulsions, and liposomes, have been widely used to enhance the antimicrobial efficacy and utilization of EOs in foods (Rao et al., 2019).

Oregano, a bushy, herbaceous perennial plant native to Europe and Central Asia, is a flavoring herb widely used throughout the world to flavor various foods and processed meals, such as salads, pizza, and sausages (Morshedloo et al., 2018). EOs extracted from the leaves and inflorescence of oregano have been claimed to have numerous useful biological activities, including antioxidant, antimicrobial, anti-inflammatory, antidiabetic, and cancer-suppressing effects (Leyva-Lopez et al., 2017). Carvacrol-rich chemotypes of oregano cover most of its natural range of biological activities, which have a vast range of applications in food industries (Emrahi et al., 2021). Carvacrol [2-methyl-5-(1-methylethyl) phenol], a monoterpenic phenol, is one of the main essential oil compounds produced by oregano plants, which exhibits significant antimicrobial activity against foodborne pathogens (Miladi et al., 2016). Cui et al. (2019) reported that the antibacterial consequences of the action of oregano essential oil (OEO) could be summarized in the following ways: changes in the permeability of the cell membrane and irreversible damage to the cell membrane; inhibition of respiratory metabolism; carvacrol, as the main component of $\mathrm{OEO}$, forming chimeras with DNA; and reducing the production of a Panton-Valentine Leukocidin (PVL) toxin.

Proteomics is the systematic evaluation of all proteins expressed by one particular organism in a given time
(Dos Santos et al., 2016). The quantitative proteomics based on chromatographic separations coupled with mass spectrometry improves the identification of pathogenic proteins in response to the treatment of antimicrobial agents. The technology is considered a useful means to identify and characterize the differential proteins of microbes treated with natural agents, which is a key strategy to understand better the antibacterial mechanism (Tang et al., 2020). Despite some reports on the antimicrobial activity of OEO, mainly related to its effects on bacterial phenotype and physiology, the change in the protein profile of foodborne bacteria caused by an OEO is unknown or less studied. Thus, in the present study, we investigated the potential antibacterial mechanism of a carvacrol-rich OEO against $S$. aureus. On the one hand, the changes in the cell membrane of $S$. aureus after exposure to an OEO were detected using a cryo-scanning electron microscope (cryo-SEM), flow cytometry, and laser confocal microscopy. On the other hand, the label-free quantitative proteomic analysis was employed to characterize the differentially expressed proteins (DEPs) between the OEO-treated and untreated groups, which could reveal the potential functions and the biological processes involved in the anti-S. aureus action of OEO.

\section{MATERIALS AND METHODS}

\section{Plant Materials, Essential Oil Extraction, and Bacterial Strains}

The aerial parts of Origanum vulgare "Hot \& Spicy" were harvested in the full-bloom stage in Nanyang, Henan Province, at the coordinates $32^{\circ} 78^{\prime} \mathrm{N}, 112^{\circ} 57^{\prime} \mathrm{E}, 116 \mathrm{~m}$ of altitude, in July 2019. Then, the aerial parts were air dried under the shade for 4 weeks. Dried samples were ground to a powder before extracting the OEO. The OEO was extracted from $100 \mathrm{~g}$ of powdered samples in $1000 \mathrm{~mL}$ of distilled water by steam distillation (Clevenger apparatus) for $3 \mathrm{~h}$ (Baranauskienë et al., 2013). The extracted OEO was dried using anhydrous sodium sulfate and stored in an amber bottle at $4^{\circ} \mathrm{C}$ until use. The S. aureus strain CGMCC 1.4519 was obtained from the China General Microbiological Culture Collection Center (Beijing, China). The strains were stored in the Luria-Bertani (LB) broth with $25 \%$ glycerol $(v / v)$ at $-80^{\circ} \mathrm{C}$. Before each experiment, the test strain was shake-cultured in LB broth for $12 \mathrm{~h}$ at $37^{\circ} \mathrm{C}$.

\section{Chemical Characterization}

The composition of OEO was analyzed by gas chromatography-mass spectrometry (GC-MS) (7890A7000B, Agilent Technologies, United States) equipped with a $30 \mathrm{~m} \times 250 \mu \mathrm{m} \times 0.25 \mu \mathrm{m}$ HP-5MS column (Agilent Technologies). Further, $1 \mu \mathrm{L}$ of the sample was injected at a split mode of $40: 1$. The injector temperature was $250^{\circ} \mathrm{C}$, and the temperature programming was as follows: the temperature remained at $40^{\circ} \mathrm{C}$ for $2 \mathrm{~min}$ and was then ramped up linearly to $77^{\circ} \mathrm{C}$ at a rate of $8^{\circ} \mathrm{C} / \mathrm{min}$; the temperature was ramped up to $150^{\circ} \mathrm{C}$ at a rate of $5^{\circ} \mathrm{C} / \mathrm{min}$, and then ramped to $185^{\circ} \mathrm{C}$ at a rate of $3^{\circ} \mathrm{C} / \mathrm{min}$, followed by ramping to $310^{\circ} \mathrm{C}$ at $60^{\circ} \mathrm{C} / \mathrm{min}$. The transfer line temperature was $280^{\circ} \mathrm{C}$, and helium was used as 
the carrier gas at a flow rate of $1.0 \mathrm{~mL} / \mathrm{min}$ through the column. The MS operating parameters were as follows: ionization energy, $70 \mathrm{eV}$; ion source temperature, $230^{\circ} \mathrm{C}$; quadrupole temperature, $150^{\circ} \mathrm{C}$; and mass range, $40-700 \mathrm{u}$. The OEO compounds were identified by comparing the National Institute of Standards and Technology 17 library spectra and retention index (RI) values. The RI values were calculated using a series of $n$-alkane (C7-C40) hydrocarbons under the same conditions. The relative percentage composition of OEO components was determined based on the peak area.

\section{Antibacterial Activity \\ Diameter of the Inhibitory Zone Assay}

The disk diffusion method was used to assess the diameter of the inhibitory zone (DIZ) of OEO on S. aureus. Briefly, $100 \mu \mathrm{L}$ of $S$. aureus suspensions (approximately $10^{7} \mathrm{CFU} / \mathrm{mL}$ ) were evenly spread onto LB agar plates. Sterilized antimicrobial disks were placed on test plates, and $6-\mu \mathrm{L}$ aliquot of pure OEO was added to the $6-\mathrm{mm}$ disks. Then, the plates were incubated at $37^{\circ} \mathrm{C}$ for $24 \mathrm{~h}$ (Marques et al., 2015). The DIZ value was measured using Vernier calipers (Airaj, Tsingtao, China).

\section{Determination of Minimum Inhibitory Concentration and Minimum Bactericidal Concentration}

The double broth dilution method described by Kang et al. (2019) was used to determine the minimum inhibitory concentration (MIC) and minimum bactericidal concentration (MBC) values. Briefly, approximately $10^{7} \mathrm{CFU} / \mathrm{mL}$ of the $S$. aureus strains were cultured in LB broths and mixed with a range of concentrations of OEO $(0.0625-8 \mathrm{mg} / \mathrm{mL})$ in test tubes. The LB without OEO was regarded as a control. Then, these tubes were incubated at $37^{\circ} \mathrm{C}$ for $24 \mathrm{~h}$. The MIC was considered as the lowest concentration of OEO at which no visible bacterial growth was observed. An $S$. aureus suspension from each tube with no visible bacterial growth was cultured on LB agar plates. The MBC was the lowest concentration of OEO that prevented the growth of bacterial colonies on the LB agar surface.

\section{Effects of Oregano Essential Oil on the S. aureus}

\section{Antibacterial Curve Assay}

The growth curve determination was performed as described by Kang et al. (2020), with slight modification. The OEO was dissolved in a sterile LB broth to obtain the final concentrations of 1/8MIC, 1/4MIC, 1/2MIC, MIC, and MBC. S. aureus CGMCC 1.4519 growth curve was determined by measuring $\mathrm{OD}_{600 \mathrm{~nm}}$ for 0 to $24 \mathrm{~h}$ at 1 -h intervals using a Bioscreen $\mathrm{C}$ Automated Microbiology Growth Curve Analysis System (Oy, Finland) at $37^{\circ} \mathrm{C}$ in $\mathrm{LB}$ broth. The $\mathrm{OD}_{600 \mathrm{~nm}}$ value of $\mathrm{LB}$ broth without $\mathrm{OEO}$ and $S$. aureus was regarded as a blank control.

\section{Cell Membrane Integrity Assay}

An S. aureus suspension (approximately $10^{7} \mathrm{CFU} / \mathrm{mL}$ ) was treated with or without $\mathrm{OEO}$ at final concentrations of $0,1 / 2$ MIC, MIC, and $\mathrm{MBC}$ at $37^{\circ} \mathrm{C}$ for $8 \mathrm{~h}$. These treated samples were washed three times with PBS and further stained with
$5 \mu \mathrm{M}$ SYTO9 and $15 \mu \mathrm{M}$ propidium iodide (PI) (Molecular Probes, Invitrogen, France) in the dark for 15 min (Kang et al., 2020). Next, the cells were washed three times with PBS and resuspended in PBS before analysis. The cell membrane integrity was measured on a MoFlo XDP flow cytometer (Beckman Coulter, Brea, CA, United States) and a confocal laser scanning microscope (CLSM; Zeiss LSM 980 with Elyra7, Jena, Germany).

\section{Cryo-Scanning Electron Microscope Analysis}

Staphylococcus aureus cells (approximately $10^{7} \mathrm{CFU} / \mathrm{mL}$ ) were treated with or without an OEO (Control, 1/2 MIC, MIC, and $\mathrm{MBC}$ ) for $8 \mathrm{~h}$ at $37^{\circ} \mathrm{C}$. The suspensions were centrifuged at $5000 \times g$ for $10 \mathrm{~min}$ at $4^{\circ} \mathrm{C}$. The harvested cells were washed three times with PBS and finally suspended in sterile water. The morphology of $S$. aureus cells treated or untreated with the OEO was observed using a cryo-SEM (Regulus 8100, Hitachi Co., Ltd., Japan) (Wu et al., 2014).

\section{Label-Free Quantitative Proteomic Analysis \\ Protein Extraction, Quantification, and Digestion}

The extracted OEO was added to $S$. aureus suspension [OEO final concentration was $0.0625 \mathrm{mg} / \mathrm{mL}(1 / 2 \mathrm{MIC})]$ and incubated for 8 h. S. aureus cultures treated without the OEO were regarded as a control. The suspensions were centrifuged at $5000 \times g$ for $10 \mathrm{~min}$ at $4^{\circ} \mathrm{C}$. The harvested cells were washed three times with PBS. The treated and untreated cultures were ground to a powder in liquid nitrogen and suspended in lysis buffer (2 M thiourea, $7 \mathrm{M}$ urea, $4 \%$ SDS, $40 \mathrm{mM}$ Tris- $\mathrm{HCl}$ ) containing $1 \mathrm{mM}$ PMSF, $2 \mathrm{mM}$ EDTA, and $10 \mathrm{mM}$ 1,4-dithiothreitol. They were then ultrasonicated on ice for $15 \mathrm{~min}$ (2-s ultrasonics/3-s pause). The lysate was centrifuged at $13,000 \times g$ for $20 \mathrm{~min}$ at $4^{\circ} \mathrm{C}$. The supernatant was transferred to ice-cold acetone and then centrifuged again at $13,000 \times g$ for $20 \mathrm{~min}$ at $4^{\circ} \mathrm{C}$. The precipitated pellets were collected and then solubilized in lysis buffer. The Bradford method was used for protein quantification. Proteins were diluted fivefold with $100 \mathrm{mM}$ triethylammonium bicarbonate and then digested with trypsin at an enzymesubstrate ratio of 1:50 $(w / w)$. Peptides were desalted using a Strata-X C18 pillar (Phenomenex Inc., CA, United States) and then dried using a vacuum centrifuge.

\section{SDS-PAGE Analysis}

The collected proteins $(20 \mu \mathrm{g})$ for each bacterial sample were mixed with $5 \times$ loading buffer and further boiled for $5 \mathrm{~min}$. The proteins were separated on $12.5 \%$ SDS-PAGE gel (constant current $14 \mathrm{~mA}, 90 \mathrm{~min}$ ). Protein bands were visualized by Coomassie Blue R-250 staining (Kang et al., 2018).

\section{LC-MS/MS Analysis}

An LC-MS/MS analysis was performed on a Thermo Orbitrap Fusion Lumos mass spectrometer (Thermo Fisher Scientific) coupled to Easy nLC-1200 nanoLC system (Thermo Fisher Scientific, Waltham, MA, United States) for $90 \mathrm{~min}$. The peptides were loaded onto a reverse phase trap column (manually packed 
reverse phase C18 column, $100 \mu \mathrm{m} \times 2.5 \mathrm{~cm}, 1.9 \mu \mathrm{m}$ particle size; $120 \AA$ pore diameter; Dr. Maisch GmbH Inc., Germany) connected to a C18-reversed-phase analytical column (manually packed reverse phase C18 column, $150 \mu \mathrm{m} \times 25 \mathrm{~cm}$ in buffer A $(0.1 \%$ formic acid $)$ and separated with a linear gradient of buffer B ( $80 \%$ acetonitrile and $0.1 \%$ formic acid) at a flow rate of $500 \mathrm{~nL} / \mathrm{min}$. The mass spectrometer was operated in the positive ion mode with the following parameters: the resolution set to $120 \mathrm{~K}$ for MS1. In MS1, the scan range was $350-1550 \mathrm{~m} / z$. The automatic gain control was $4 \mathrm{E} 5$, and the charge state was $2-7$. In MS2, the normalized collision energy was set to $32 \%$. Ions were broken by higher collision dissociation and then analyzed by Orbitrap with AGC targets set at 5E4.

The MS raw data for each sample were combined and searched using the MaxQuant 1.5.3.17 software for identification and quantitation analysis. The mass spectrometry proteomics data have been deposited to the ProteomeXchange Consortium via the PRIDE (Perez-Riverol et al., 2019) partner repository with the dataset identifier PXD028357.

\section{Bioinformatics Analysis}

Cluster $3.0^{1}$ and Java Treeview software ${ }^{2}$ were used to carry out a hierarchical clustering analysis. A heatmap was often presented as a visual aid in addition to the dendrogram. The protein sequences of the selected DEPs were locally searched using the NCBI BLAST+ client software and InterProScan to find homolog sequences. Then, Gene Ontology (GO) terms

${ }^{1}$ http://bonsai.hgc.jp/ mdehoon/software/cluster/software.htm

${ }^{2} \mathrm{http}: / /$ jtreeview.sourceforge.net were mapped, and sequences were annotated using the software program Blast2GO. The GO annotation results were plotted using R scripts. Following annotation steps, the studied proteins were blasted against the online Kyoto Encyclopedia of Genes and Genomes (KEGG) database ${ }^{3}$ to retrieve their KEGG orthology identifications and were subsequently mapped to pathways in KEGG. The enrichment analysis was applied based on the Fisher exact test, considering the whole quantified proteins as the background dataset. Benjamini-Hochberg correction for multiple testing was further applied to adjust derived $P$-values. Only functional categories and pathways with $P$-values under a threshold of 0.05 were considered significant.

\section{Statistical Analysis}

All experiments were carried out in triplicate independently. All data were presented as the mean \pm standard deviation. Differences between means were tested using one-way analysis of variance and LSD test and analyzed using IBM SPSS software (version 19.0; SPSS Inc., Chicago, IL, United States). A Pvalue $\leq 0.05$ indicated a significant difference.

\section{RESULTS}

\section{Chemical Composition of Oregano Essential Oil}

The chemical composition analysis of the OEO via GC-MS resulted in identifying 27 chemical compounds (Figure $\mathbf{1}$

\footnotetext{
${ }^{3}$ http://geneontology.org/
}

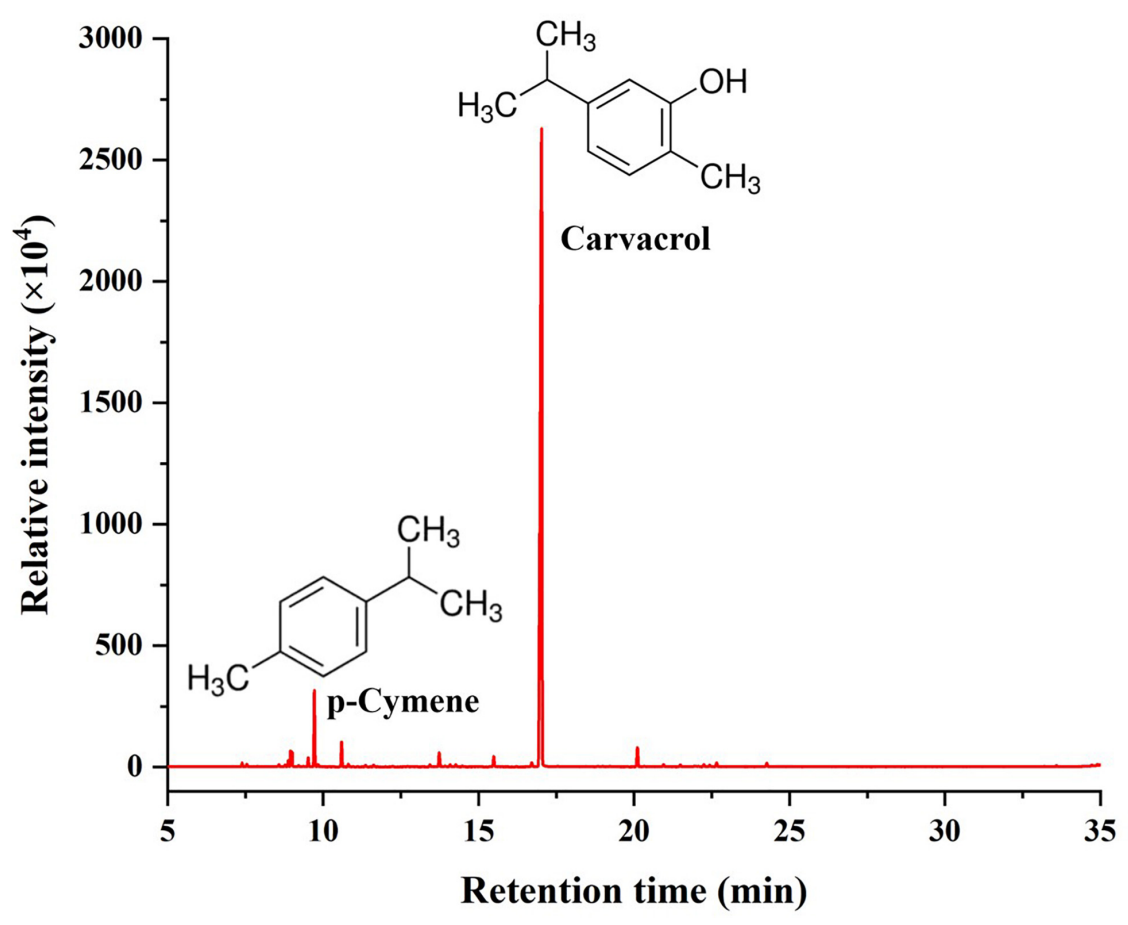

FIGURE 1 | Chemical composition of OEO. 
and Table 1). The most abundant bioactive components were monoterpenes and sesquiterpenes. Monoterpene carvacrol was the main compound, which comprised $84.38 \%$ of the identified compounds. In addition, several other natural compounds were reported, including $p$-cymene, $\gamma$-terpinene, $\beta$-caryophyllene, and terpinen-4-ol. These compounds comprised 5.07\%, $1.7 \%, 1.56 \%$, and $1.06 \%$ of all compounds identified in the OEO, respectively.

\section{Antibacterial Effects of Oregano Essential Oil Against S. aureus}

Table 2 shows the DIZ, MIC, and MBC values of the OEO against S. aureus. As shown in Table 2, the carvacrol-rich OEO had a potent inhibitory effect against $S$. aureus. The average DIZ value was $29.1( \pm 0.6) \mathrm{mm}$, and the MIC and MBC of OEO against $S$. aureus were 0.125 and $0.25 \mathrm{mg} / \mathrm{mL}$, respectively.

The effects of OEO at 1/8MIC, 1/4MIC, 1/2MIC, MIC, and $\mathrm{MBC}$ on the growth of $S$. aureus are shown in Figure 2. All the OEO concentrations showed inhibition against $S$. aureus but with different degrees. The growth of $S$. aureus was completely inhibited in the presence of OEO at the MIC and MBC in the LB broth. The OEO at $1 / 2$ MIC decreased the maximal cell populations of $S$. aureus compared with the control group within $24 \mathrm{~h}$. The OEO concentrations within 1/4 MIC or 1/8 MIC showed slightly inhibitory effects against the $S$. aureus growth.
These results demonstrated that the concentration and treatment time of OEO had great influences on antibacterial effects.

\section{Effects of Oregano Essential Oil on the Cell Membrane of S. aureus}

Cryo-SEM observation allows one to study the alterations in several compartments in the cell membrane; it has been used to offer direct evidence of the ability of EOs to disrupt the structure of microbial cells (Rao et al., 2019). Figure 3A shows the changes in the cell morphology of $S$. aureus. The untreated $S$. aureus cells had a regular and smooth surface with no visible fractures and a typically spherical or elliptical Staphylococcus morphology. When the $S$. aureus cells were treated with OEO at 0.0625 (1/2MIC), 0.125 (MIC), and 0.25 (MBC) $\mathrm{mg} / \mathrm{mL}$, the bacterial cell surfaces showed more shrinkage compared with normal $S$. aureus cells and the number of $S$. aureus cells decreased with the increasing OEO concentration.

Furthermore, we used flow cytometry to determine the cell membrane integrity and cell viability of $S$. aureus treated with the OEO. Figure $\mathbf{3 B}$ shows the changes in cell viability; in this figure, R1, R2, and R4 regions correspond to dead, injured, and intact $S$. aureus cells, respectively. The control group showed approximately $98.6 \%$ S. aureus cells having intact cell membranes. When the $S$. aureus cells were treated with the $\mathrm{OEO}$ at 1/2 MIC and MIC levels, the percentage of injured

TABLE 1 | Chemical composition (\%) of OEO.

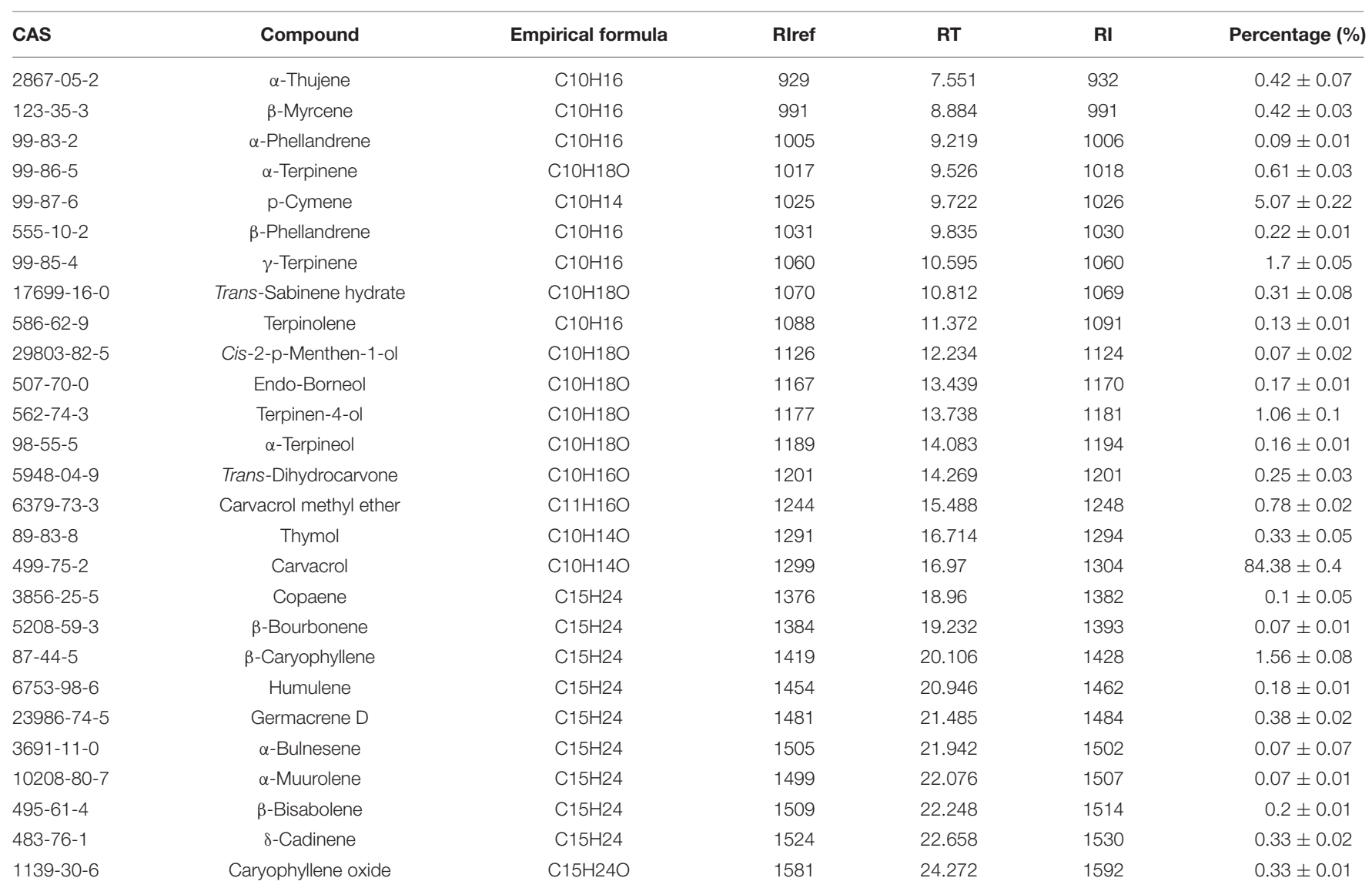


TABLE 2 | Diameter of the inhibition zone (DIZ), minimum inhibitory concentration $(\mathrm{MIC})$, and minimum bactericidal concentration (MBC) of OEO against $S$. aureus.

\begin{tabular}{llllllllllll}
\hline Bacteria & DIZ (mm) & \multicolumn{7}{c}{ Concentrations of OEO (mg/mL) } \\
\cline { 2 - 9 } & & 0 & $\mathbf{0 . 0 6 2 5}$ & $\mathbf{0 . 1 2 5}$ & $\mathbf{0 . 2 5}$ & $\mathbf{0 . 5}$ & $\mathbf{1}$ & $\mathbf{2}$ & $\mathbf{4}$ & $\mathbf{8}$ \\
\hline S. aureus & $29.1 \pm 0.6$ & ++ & ++ & + & + & - & - & - & - & - & - \\
\hline $\begin{array}{l}\text { "++" means observed growth of bacteria, "+" means no visible growth of bacteria, } \\
\text { and "-" no cell colonies on the surface of LB agar. }\end{array}$
\end{tabular}

cells distributed in the R2 quadrant was $96.76 \%$ and $81.98 \%$, respectively. When the $S$. aureus cells were treated with the OEO at MIC and MBC levels, the percentage of dead cells distributed in the R1 quadrant was $16.4 \%$ and $43.56 \%$, respectively. CLSM further verified this result. The specific performance was that the green fluorescence in the images gradually decreased and the red fluorescence gradually increased with the increase in the OEO concentration (Figure 3C).

\section{Protein Identification and Quantification}

The label-free quantitative proteomic analysis was used to detect DEPs between control and treatment groups to explore the potential molecular mechanisms of the antibacterial effects of OEO treatment on S. aureus. As shown in Figure 4A, 67,343 spectra were produced and matched, and 9379 peptides were identified, of which 7429 were unique peptides. In addition, the total number of identified proteins was 1268 , and the number of proteins that could be quantified was 1213 . The cluster analysis of control and OEO-treatment groups is shown in Figure 4B. The result indicated only minor variations among the three replicates, but the OEO treatment differed substantially from the control.

\section{Distribution of Identified Differentially Expressed Proteins}

A Venn diagram showed the details of all 1268 proteins between the two groups, including 1178 shared DEPs (Figure 4C). Furthermore, the volcano plot shown in Figure 4C depicts $\log _{2}$ (treatment/control) against $-\log _{10}(P$-value $)$ representing the possibility for DEPs. In this figure, DEPs were regarded as proteins with $\geq 2 / 3$ or $\leq 2 / 3$ fold change and $P$-value less than 0.05. As shown in Figure $\mathbf{4 B}$, the red points and blue dots indicate upregulated and downregulated DEPs, respectively. The gray dots indicate unchanged proteins. Based on this, 56 DEPs were confirmed, of which 26 were significantly upregulated and 30 downregulated. Also, all the DEPs were transformed into a heat map. A hierarchical clustering analysis with the Euclidean distance algorithm was employed to analyze DEP expression patterns between control and OEO-treatment groups. As shown in Figure 4D, blue represents downregulated DEPs, red represents upregulated DEPs, and white represents no detectable expression change.

The DEPs in the control and OEO-treatment groups are listed in Table 3. DEPs with an fold change (FC) value of more than 2 included A5IV11 (50S ribosomal protein L36), A0A380DL04 (ribitol-5-phosphate cytidylyltransferase), A0A380DI91 (ribokinase), A0A033UKY8 (50S ribosomal protein L7/L12), A0A0D1EWN0 (phosphoribosylformylglycinamidine synthase subunit PurS), A5IPU8 (30S ribosomal protein S18), A8Z216 (50S ribosomal protein L33 2), and A0A1Q8DDL3 (cysteine synthase). The protein encoded by cysM in $S$. aureus was sequentially and functionally homologous to the $O$-acetylserine (thiol)-lyase B family of cysteine synthase proteins. A mutation of $c y s M$ caused increased $S$. aureus sensitivity to tellurite, hydrogen peroxide, acid, and diamide but decreased the

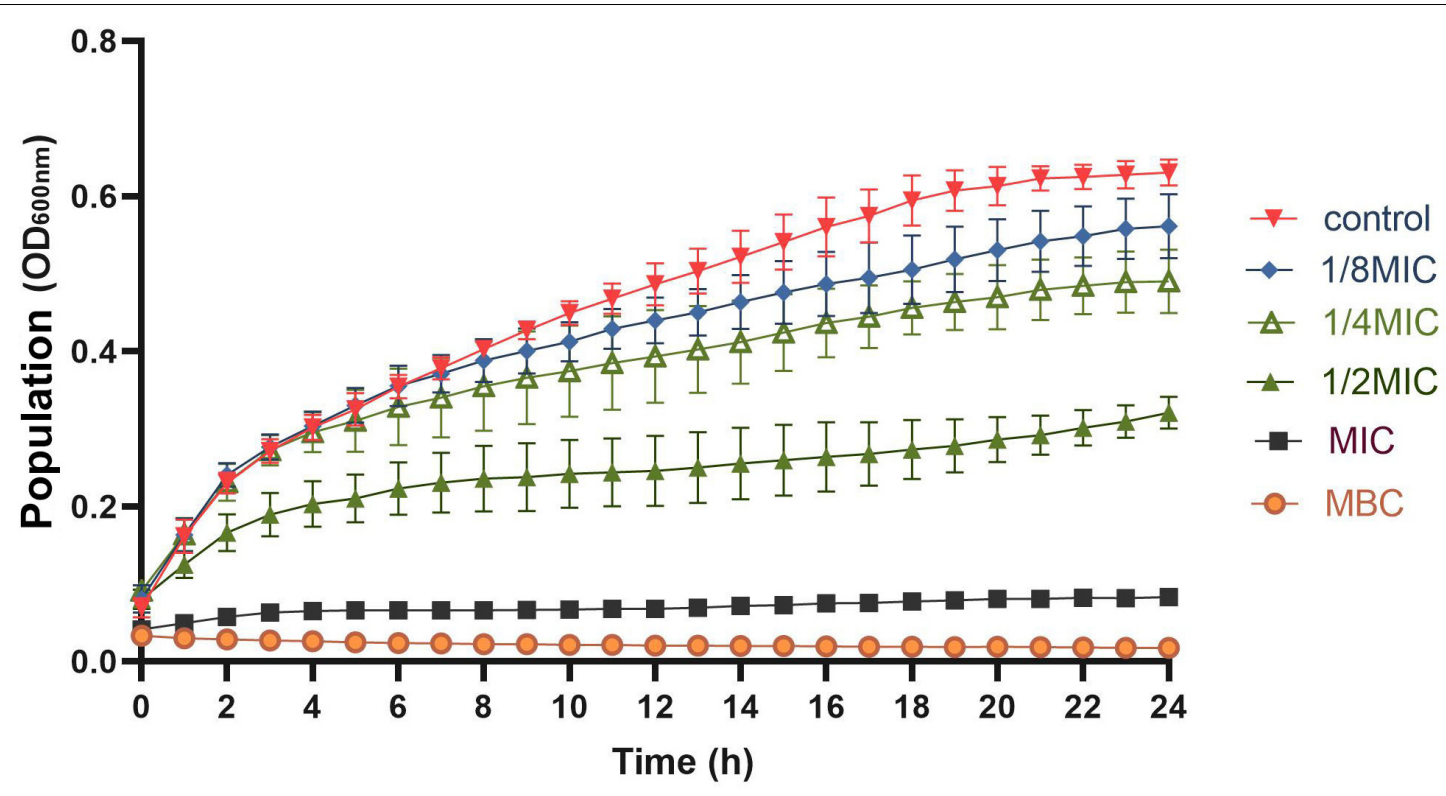

FIGURE 2 | Growth curve of OEO against S. aureus in LB broth at $37^{\circ} \mathrm{C}$; OEO concentrations includes 0 (control), $1 / 8 \mathrm{MIC}(0.015625 \mathrm{mg} / \mathrm{mL}), 1 / 4 \mathrm{MIC}$ $(0.03125 \mathrm{mg} / \mathrm{mL}), 1 / 2 \mathrm{MIC}(0.0625 \mathrm{mg} / \mathrm{mL}), \mathrm{MIC}(0.125 \mathrm{mg} / \mathrm{mL})$, and $\mathrm{MBC}(0.25 \mathrm{mg} / \mathrm{mL})$. 

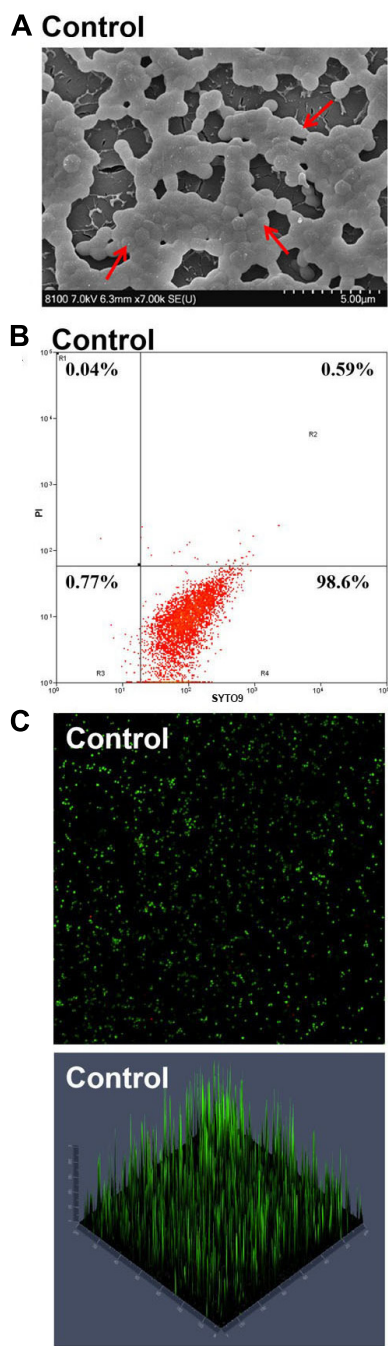
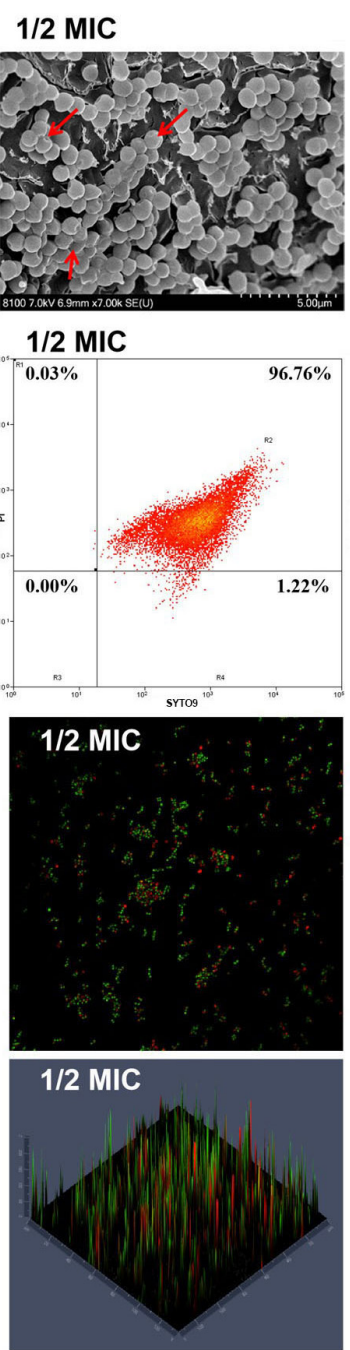

MIC
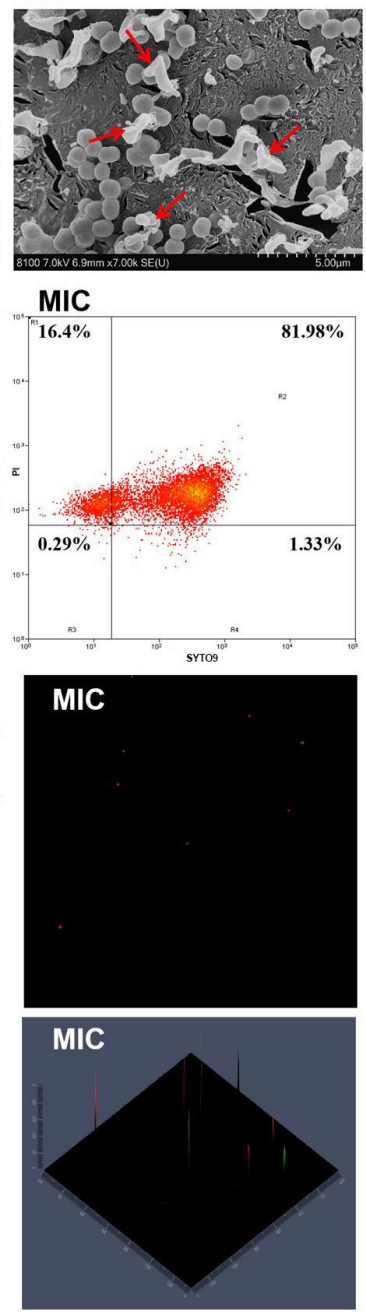
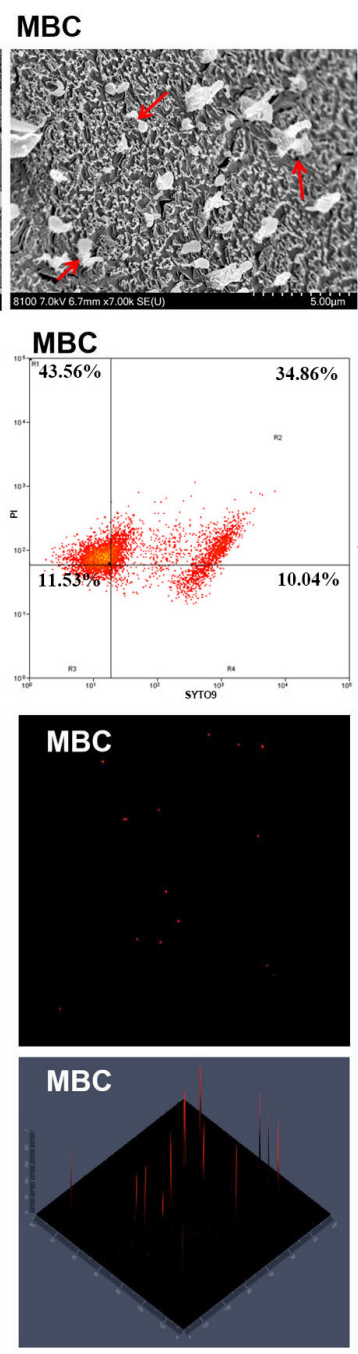

FIGURE 3 | Cryo-SEM images of S. aureus after treatment with the OEO for $8 \mathrm{~h}$ at different concentrations of $1 / 2 \mathrm{MIC}$, MIC, and MBC (A). Fluorescence dot images of $S$. aureus cells exposed to the OEO at $0,1 / 2 \mathrm{MIC}$, MIC, and MBC, as analyzed by FCM (B). CLSM showed the S. aureus viability treated with different concentrations of OEO. The cells stained with SYTO9 are labeled green, while the cells stained with PI are labeled red (C).

ability of $S$. aureus to recover from starvation under amino acid- or phosphate-limiting conditions (Lithgow et al., 2004). Among these DEPs, A0A1Q8DDL3 protein was downregulated, suggesting that the OEO might inhibit the growth of $S$. aureus by decreasing the activity of cysteine synthase. Thus, GO and KEGG enrichment analyses were further carried to understand the biological functions regarding the inhibition of $S$. aureus by the treatment of $1 / 2 \mathrm{MIC}$ OEO.

\section{Gene Ontology Functional Classification and Kyoto Encyclopedia of Genes and Genomes Pathway Analysis of Differentially Expressed Proteins}

A GO enrichment analysis was carried out to identify the biological processes, cellular components, and molecular functions of identified proteins. The number of proteins involved in each of these function terms is listed in Figure 5A. As illustrated in Figure 5A, metabolic process (GO:0008152) and cellular process (GO:0009987) were the main distributed terms in the biological process ontology. For the ontology of molecular function, most DEPs were mainly gathered at the following terms: catalytic activity (GO:0003824) and binding (GO:0005488). In the cellular component ontology, the main terms were cell (GO:0005623) and cell part (GO:0044464).

A KEGG pathway analysis was used to collect information regarding protein functions in the metabolic processes to explore the specific biological events of the DEPs. The distribution of the enriched KEGG pathway is shown in Figure 5B. As shown in the figure, the Rich factor represented the ratio of the number of DEPs annotated to the KEGG pathway category to the number of all identified proteins annotated to the category. The ordinate means the description of the main KEGG pathway; the bubble color indicates the significance of 


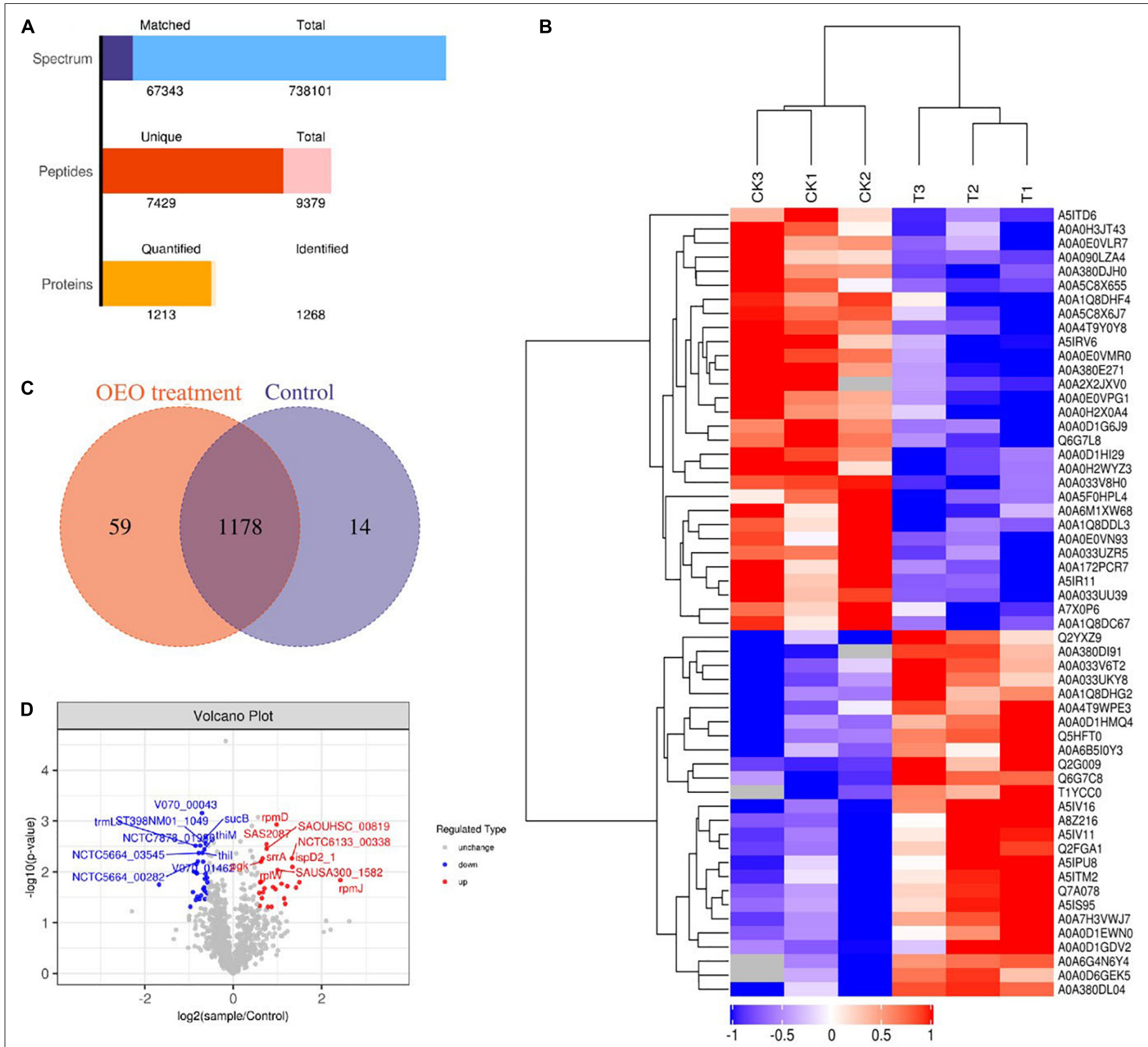

FIGURE 4 | (A) Number of peptides that matched to proteins and number of proteins quantified and identified in this study. (B) Venn diagrams indicate overlapping differentially expressed proteins (DEPs) between control and OEO-treatment groups. (C) Volcano of DEPs. (D) Cluster analysis of protein expression profiles.

the enriched KEGG pathway, that is, the closer the color is to red, the smaller the $P$-value and the higher the significance level of the enrichment of the corresponding metabolic pathway. Based on this, the ribosome (ko03010) pathway enriched the largest number of DEPs and exhibited a higher significance level. Among these enriched pathways, chlorocyclohexane and chlorobenzene degradation (ko00361), styrene degradation (ko00643), ribosome biogenesis in eukaryotes (ko03008), and AMPK signaling pathway (ko04152) had a high value of the Rich factor. In addition, amino acid metabolism, including valine, leucine, and isoleucine biosynthesis (ko00290) and phenylalanine, tyrosine, and tryptophan biosynthesis (ko00400), was identified as the important enriched pathway, suggesting that the OEO might interfere with the amino acid metabolism of S. aureus.

\section{DISCUSSION}

Oregano essential oils are considered as the highly complex mixtures of bioactive compounds, in which the preponderant constituents are terpenes, generally mono- and sesquiterpenes. The main terpenes identified in the different species of oregano are carvacrol, thymol, $\gamma$-terpinene, and $p$-cymene, followed by 
TABLE 3 | Some bacterial response-related DEPs of S. aureus after 1/2-OEO treatment.

\begin{tabular}{|c|c|c|c|c|}
\hline Protein ID & Ratio & $P$-value & Change & Protein description \\
\hline A0A033UKY8 & 2.33 & 0.019 & Up & $50 S$ ribosomal protein L7/L12 \\
\hline A0A033UU39 & 0.62 & 0.006 & Down & Glutamate dehydrogenase \\
\hline A0A033UZR5 & 0.62 & 0.004 & Down & Probable tRNA sulfurtransferase \\
\hline A0A033V6T2 & 1.94 & 0.022 & Up & Elongation factor Ts \\
\hline A0A033V8H0 & 0.61 & 0.001 & Down & Pyruvate dehydrogenase E1 component subunit beta \\
\hline A0A090LZA4 & 0.51 & 0.049 & Down & 3-Deoxy-7-phosphoheptulonate synthase \\
\hline AOAOD1EWNO & 2.26 & 0.042 & Up & Phosphoribosylformylglycinamidine synthase subunit PurS \\
\hline A0A0D1G6J9 & 0.54 & 0.010 & Down & Rqc2 homolog $\mathrm{RqcH}$ \\
\hline A0A0D1GDV2 & 1.82 & 0.049 & Up & DM13 domain-containing protein \\
\hline AOAOD1HI29 & 0.55 & 0.003 & Down & Putative tRNA (cytidine(34)-2-O)-methyltransferase \\
\hline A0A0D1HMQ4 & 1.52 & 0.016 & Up & Molybdopterin molybdenumtransferase \\
\hline A0A0D6GEK5 & 1.72 & 0.049 & Up & Esterase Ydil \\
\hline AOAOEOVLR7 & 0.63 & 0.022 & Down & N-Acyl-L-amino acid amidohydrolase \\
\hline AOAOEOVMRO & 0.65 & 0.003 & Down & Transcriptional regulator, MarR family \\
\hline AOAOEOVN93 & 0.60 & 0.029 & Down & Coenzyme A biosynthesis bifunctional protein CoaBC \\
\hline AOAOH2WYZ3 & 0.65 & 0.011 & Down & NifU domain protein \\
\hline AOAOH3JT43 & 0.59 & 0.034 & Down & Glycine cleavage system $\mathrm{H}$-like protein \\
\hline A0A172PCR7 & 0.64 & 0.014 & Down & Triacylglycerol lipase \\
\hline A0A1Q8DC67 & 0.67 & 0.016 & Down & TRAM domain-containing protein \\
\hline A0A1Q8DDL3 & 0.31 & 0.018 & Down & Cysteine synthase \\
\hline A0A1Q8DHF4 & 0.66 & 0.026 & Down & Molybdenum cofactor biosynthesis protein B \\
\hline A0A1Q8DHG2 & 1.86 & 0.020 & Up & Ferrichrome ABC transporter substrate-binding protein \\
\hline AOA380DI91 & 2.51 & 0.005 & Up & Ribokinase \\
\hline A0A380DJHO & 0.57 & 0.006 & Down & Exotoxin 15 \\
\hline AOA380DL04 & 2.52 & 0.008 & Up & Ribitol-5-phosphate cytidylyltransferase \\
\hline A0A380E271 & 0.58 & 0.004 & Down & Similar to hydrolase (HAD superfamily) \\
\hline A0A4T9WPE3 & 1.50 & 0.026 & Up & Dihydroxyacetone kinase subunit $L$ \\
\hline AOA4T9Y0Y8 & 0.65 & 0.002 & Down & Dihydrolipoyllysine-residue succinyltransferase component of 2-oxoglutarate dehydrogenase complex \\
\hline A0A5C8 $\times 655$ & 0.57 & 0.031 & Down & Iron-hydroxamate ABC transporter substrate-binding protein \\
\hline A0A5C8 $\times 6 J 7$ & 0.56 & 0.010 & Down & Hyperosmolarity resistance protein Ebh (fragment) \\
\hline A0A5FOHPL4 & 0.53 & 0.025 & Down & Autolysin \\
\hline A0A6B5IOY3 & 1.51 & 0.046 & Up & ATP-binding cassette domain-containing protein \\
\hline A0A6M1XW68 & 0.63 & 0.020 & Down & Recombinase RecT (fragment) \\
\hline AOA7H3WWJ7 & 1.54 & 0.006 & Up & Phosphoglycerate kinase \\
\hline A5IPU8 & 2.22 & 0.033 & Up & $30 S$ ribosomal protein $\mathrm{S} 18$ \\
\hline A5IR11 & 0.56 & 0.007 & Down & Glycine cleavage system $\mathrm{H}$ protein \\
\hline A5IRV6 & 0.66 & 0.013 & Down & Phosphoribosylformylglycinamidine synthase subunit PurL \\
\hline A5IS95 & 1.63 & 0.021 & Up & DNA-directed RNA polymerase subunit omega \\
\hline A5ITD6 & 0.56 & 0.036 & Down & Uridine kinase \\
\hline A5ITM2 & 1.57 & 0.033 & Up & ATP-dependent 6-phosphofructokinase \\
\hline A5IV11 & 5.36 & 0.015 & Up & $50 S$ ribosomal protein L36 \\
\hline A5IV16 & 1.97 & 0.001 & Up & $50 S$ ribosomal protein L30 \\
\hline $\mathrm{A} 7 \times \mathrm{OP} 6$ & 0.64 & 0.034 & Down & UDP-N-acetylmuramoyl-L-alanyl-D-glutamate-L-Iysine ligase \\
\hline A8Z216 & 2.13 & 0.017 & Up & $50 S$ ribosomal protein L33 2 \\
\hline Q2FGA1 & 2.00 & 0.009 & Up & UPF0337 protein SAUSA300_1582 \\
\hline Q2G009 & 1.69 & 0.004 & Up & Cold shock protein CspA \\
\hline Q2YXZ9 & 1.59 & 0.025 & Up & Probable CtpA-like serine protease \\
\hline Q5HFT0 & 1.58 & 0.005 & Up & Transcriptional regulatory protein SrrA \\
\hline Q6G7C8 & 1.68 & 0.003 & Up & Zinc-type alcohol dehydrogenase-like protein SAS2087 \\
\hline Q6G7L8 & 0.64 & 0.004 & Down & Hydroxyethylthiazole kinase \\
\hline Q7A078 & 1.55 & 0.016 & Up & $50 S$ ribosomal protein $L 23$ \\
\hline
\end{tabular}



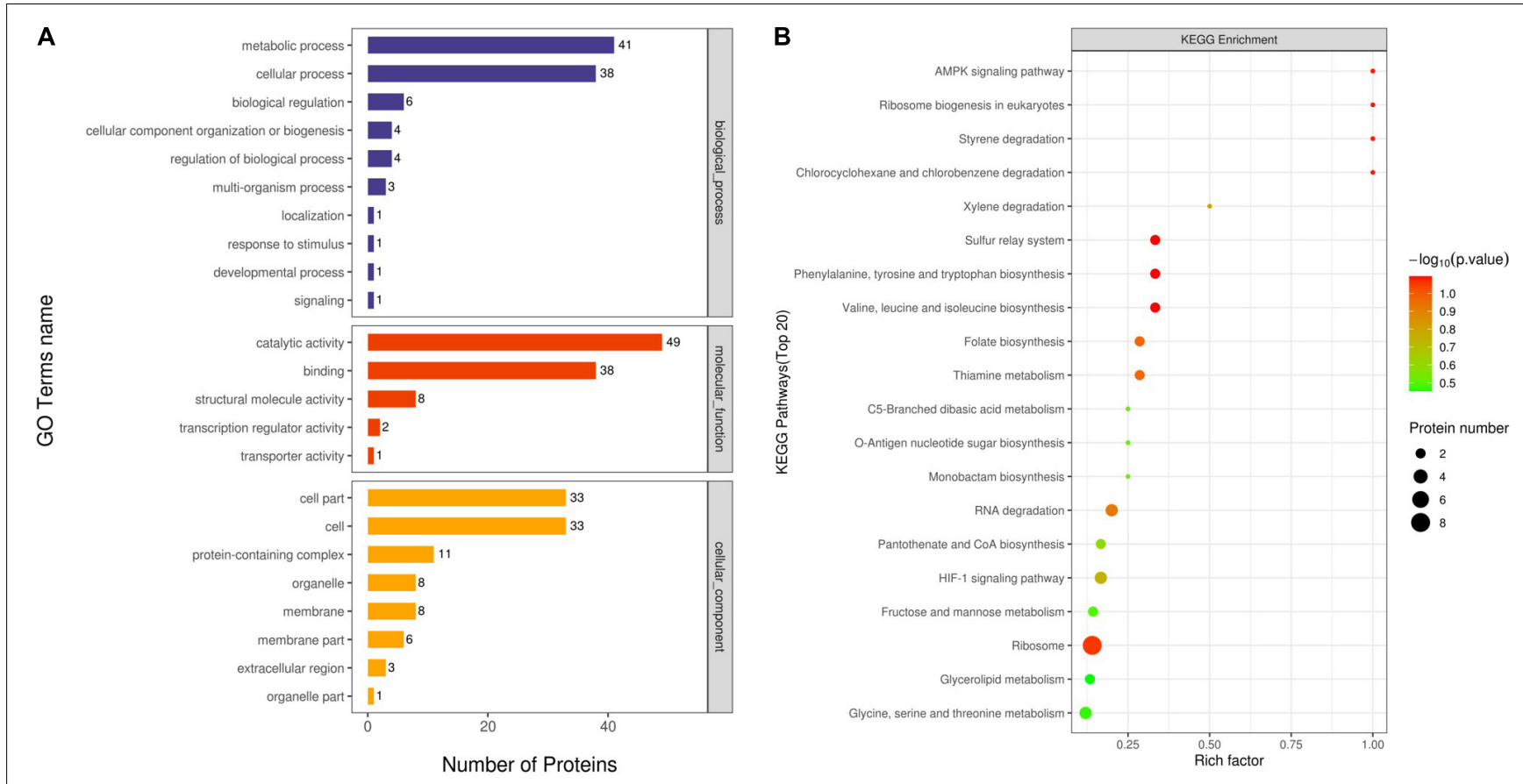

FIGURE 5 | Gene ontology (GO) analysis of all DEPs (A). Proteins were classified according to biological process, cellular component, and molecular function. The top terms of the KEGG pathway for DEPs for OEO treatment-vs.-control (B).

terpinen-4-ol, linalool, $\beta$-myrcene, trans-sabinene hydrate, and $\beta$-caryophyllene (Leyva-Lopez et al., 2017), which was consistent with the chemical composition of OEO identified in this study. Carvacrol was present in the essential oil of $O$. vulgare subspecies: subsp. hirtum and subsp. gracile as the main components. These two subspecies were considered to be among the richest sources of EOs and carvacrol in the so-called oregano world (Emrahi et al., 2021). They suggested that under purposive or regulated water deficiency stresses, the subsp. hirtum yielded the higher EO content (70\% higher than subsp. gracile), carvacrol content (20\% higher), and dry material (15\% higher) (Emrahi et al., 2021). Lambert et al. (2001) reported that the mixtures of carvacrol and thymol gave an additive effect, and the overall inhibition by the OEO could be attributed mainly to the additive antimicrobial action of these two compounds against Pseudomonas aeruginosa and S. aureus. Miladi et al. (2016) found that carvacrol and thymol served as the potential sources of the efflux pump inhibitor in foodborne pathogens. In addition, carvacrol can be regarded as an effective quorum-sensing inhibitor to combat the virulence and the biofilm formation of pathogenic bacteria on the surface of stainless steel (Tapia-Rodriguez et al., 2017). Therefore, exploring the antibacterial mechanism of carvacrol-rich OEO was of great significance for the further development of this natural product resource.

Previous reports confirmed the antimicrobial effect of OEO against foodborne pathogens and spoilage organisms, such as Bacillus coagulans, Bacillus cereus, Bacillus subtilis, Escherichia coli, Pseudomonas aeruginosa, Vibrio cholerae, Listeria monocytogenes, S. aureus, Salmonella typhimurium, and Alicyclobacillus spp. (Haberbeck et al., 2012;
Gonçalves Cattelan et al., 2013; Dutra et al., 2019; Dogruyol et al., 2020; Das et al., 2021). These results suggested that the OEO had potential spectral antibacterial properties. Other studies suggested that the OEO exhibited the inhibition of multiple targets against drug-resistant strains and multidrug-resistant strains, especially methicillin-resistant $S$. aureus (MRSA) (Nostro et al., 2004; Cui et al., 2019). Carvacrol at sub-inhibitory concentrations significantly inhibited the formation of mono- or dual-species biofilms by $P$. fluorescens and $S$. aureus by reducing quorum-sensing autoinductor2 (Wang et al., 2020). Obviously, the OEO showed great advantages as an effective natural antibacterial agent to combat the antibiotic resistance and capacity for biofilm formation of foodborne pathogens.

The bacterial cell membrane is an essential active barrier structure between the cytoplasm and the extracellular medium that is important for maintaining energy transduction and cellular metabolism (Sanchez et al., 2010). Many natural agents that kill bacteria are mediated by a membrane damage mechanism. We studied the integrity of the cell membrane with the help of fluorescent probe labeling to further investigate the action mechanism of $\mathrm{OEO}$ on the cell membranes of S. aureus. PI is a fluorescent probe impermeable to cell membranes, while SYTO9 is a fluorescent probe permeable to cell membranes. The former binds to injured or dead cells and presents red fluorescence, while the latter binds to intact cells and presents green fluorescence. The two are often used in combination to assess bacterial cell membrane integrity and cell viability (Shi et al., 2016; Kang et al., 2020). Our results demonstrated that the OEO disrupted the 
membrane integrity of $S$. aureus. Shi et al. (2016) reported that syringic acid caused cell membrane hyperpolarization and changes in the cellular morphology of Cronobacter sakazakii. Kang et al. (2019) reported that the peppermint essential oil damaged the cell membranes of $S$. aureus. These finds supported the integrity results of the cell membrane damage in present study.

Proteomics analysis is a powerful technique for the identification of DEPs. Here, the label-free proteomic analysis revealed that OEO-inhibited growth of $S$. aureus might be due to the disordered effect of protein synthesis and amino acid metabolism. Based on a KEGG pathway analysis, the ribosome (ko03010) pathway enriched the largest number of DEPs. Ribosomes are organelles playing a vital role in protein synthesis. Other studies also suggest that interference with the ribosome pathway is an important means for natural products to exhibit effective antibacterial effects (Kang et al., 2020, 2021). In addition, the expression of A0A380DJH0 (exotoxin 15) protein was significantly inhibited by OEO treatment. Staphylococcal food poisoning caused by the ingestion of staphylococcal enterotoxins produced by enterotoxigenic strains of $S$. aureus has become a serious concern worldwide (Hennekinne et al., 2012). Thus, the findings on the inhibition of exotoxins by the OEO were obviously exciting. The OEO exhibited multiple targets for the inhibition of $S$. aureus according to the number and functional distribution of DEPs. Hua et al. (2018) reported that the inhibition of ribosome formation was the main mechanism of aspidinol killing $S$. aureus; the inhibition of amino acid synthesis and the reduction of virulence factors played a secondary role. Disordering the amino acid metabolism was considered a main antibacterial mechanism of $\mathrm{OEO}$ against S. aureus. Tang et al. (2020) indicated that the Amomum villosum Lour. essential oil affected the carbohydrate and amino acid metabolism in MRSA. The Blumea balsamifera (L.) essential oil disordered amino acid metabolism, physiological function and inhibited the synthesis of nucleic acids and proteins, of S. aureus (Yang et al., 2021). Overall, the present study provided some exciting results regarding the potent bactericidal effect of a carvacrol-rich OEO and its possible mechanisms of action. The OEO showed great potential in causing metabolic disorders, especially affecting bacterial protein synthesis and amino acid metabolism.

Sarengaowa et al. (2019) found that the DEPs generated from L. monocytogenes treated without and with thyme essential oil were mainly related to cellular processes, environmental information processing, genetic information processing, human diseases, metabolism, organismal systems. In accordance with the treated and untreated Salmonella Enteritidis, Barbosa et al. (2020) pointed out that the DEPs belonged to four distinct categories by GO (molecular function, biological process, cellular component, and protein class) and regulatory activity with greater change in expression in the Origanum vulgare essential oil, carvacrol, and thymol treatments. Tang et al. (2020) found that $48 \%$ of proteins were related to catalytic activity and $34 \%$ were related to binding; also, these DEPs were ranked from high to low and were related to the cellular process (32\%), metabolic process $(30 \%)$, and localization (18\%), by the GO enrichment analysis of DEGs generated by control and Amomum villosum Lour. essential oiltreated MRSA groups. These results were similar to the result obtained in this study, indicating that the inhibitory effect of OEO on $S$. aureus might be closely related to the terms such as catalytic activity and binding.

\section{CONCLUSION}

In conclusion, a carvacrol-rich OEO extracted from O. vulgare "Hot \& Spicy" demonstrated potent antimicrobial activity against $S$. aureus. The OEO appeared to some intuitive mechanisms of action: decreased maximal bacterial populations, decreased bacterial viability, and damage to the cell membrane. The labelfree quantitative proteome analysis was used as a powerful technique to explore further the changes in the protein expression of $S$. aureus induced by the OEO treatment. Several identified DEPs were associated with antibacterial mechanisms related to interference on the pathway of ribosome and amino acid metabolism, which broadened our understanding of the molecular mechanisms underlying the response of $S$. aureus under the carvacrol-rich OEO stress. Future studies should investigate the bactericidal effect of the OEO on $S$. aureus in different food matrices and make it more applicable through nanotechnology.

\section{DATA AVAILABILITY STATEMENT}

The mass spectrometry proteomics data have been deposited to the ProteomeXchange Consortium via the PRIDE partner repository with the dataset identifier PXD028357 (http:// www.ebi.ac.uk/pride; username: reviewer_pxd028357@ebi.ac.uk; password: uqrrJEuD).

\section{AUTHOR CONTRIBUTIONS}

YH analyzed the data, wrote the manuscript, and performed the experiments. JL proofread the revised manuscripts. LS supervised the experiments and provided financial support of this study. All authors contributed to manuscript revision and approved the submitted version.

\section{FUNDING}

This work was supported by the Strategic Priority Research Program of the Chinese Academy of Sciences (Grant No. XDA26040306).

\section{ACKNOWLEDGMENTS}

We thank Zhuang Lu, Ph.D., Xiuping Xu, Ph.D., Shuhua Yang, Ph.D., Jingquan Li, Ph.D., from Plant Science Facility of the Institute of Botany, Chinese Academy of Sciences for their excellent technical assistance of this study. 


\section{REFERENCES}

Baranauskienë, R., Venskutonis, P. R., Dambrauskienë, E., and Viškelis, P. (2013). Harvesting time influences the yield and oil composition of Origanum vulgare $\mathrm{L}$. ssp. vulgare and ssp. hirtum. Ind. Crops Prod. 49, 43-51. doi: 10.1016/j.indcrop. 2013.04.024

Barbosa, L. N., Alves, F. C. B., Andrade, B., Albano, M., Rall, V. L. M., Fernandes, A. A. H., et al. (2020). Proteomic analysis and antibacterial resistance mechanisms of Salmonella Enteritidis submitted to the inhibitory effect of Origanum vulgare essential oil, thymol and carvacrol. J. Proteomics 214:103625. doi: 10.1016/j.jprot.2019.103625

Cui, H., Zhang, C., Li, C., and Lin, L. (2019). Antibacterial mechanism of oregano essential oil. Ind. Crops Prod. 139:111498. doi: 10.1016/j.indcrop.2019.111498

Das, S., Chourashi, R., Mukherjee, P., Kundu, S., Koley, H., Dutta, M., et al. (2021). Inhibition of growth and virulence of Vibrio cholerae by carvacrol, an essential oil component of Origanum spp. J. Appl. Microbiol. 131, 1147-1161. doi: $10.1111 /$ jam.15022

Dogruyol, H., Mol, S., and Cosansu, S. (2020). Increased thermal sensitivity of Listeria monocytogenes in sous-vide salmon by oregano essential oil and citric acid. Food Microbiol. 90:103496. doi: 10.1016/j.fm.2020.103496

Dos Santos, B. S., Da Silva, L. C., Da Silva, T. D., Rodrigues, J. F., Grisotto, M. A., Correia, M. T., et al. (2016). Application of omics technologies for evaluation of antibacterial mechanisms of action of plant-derived products. Front. Microbiol. 7:1466. doi: 10.3389/fmicb.2016.01466

Dutra, T. V., Castro, J. C., Menezes, J. L., Ramos, T. R., Do Prado, I. N., Machinski, M., et al. (2019). Bioactivity of oregano (Origanum vulgare) essential oil against Alicyclobacillus spp. Ind. Crops Prod. 129, 345-349. doi: 10.1016/j.indcrop.2018. 12.025

Emrahi, R., Morshedloo, M. R., Ahmadi, H., Javanmard, A., and Maggi, F. (2021). Intraspecific divergence in phytochemical characteristics and drought tolerance of two carvacrol-rich Origanum vulgare subspecies: subsp. hirtum and subsp. gracile. Ind. Crops Prod. 168:113557. doi: 10.1016/j.indcrop.2021.113557

Gonçalves Cattelan, M., Bonatto Machado De Castilhos, M., Juliana Pinsetta Sales, P., and Leite Hoffmann, F. (2013). Antibacterial activity of oregano essential oil against foodborne pathogens. Nutr. Food Sci. 43, 169-174. doi: 10.1108/ 00346651311313544

Haberbeck, L. U., Alberto Da Silva Riehl, C., De Cássia Martins Salomão, B., and Falcão De Aragão, G. M. (2012). Bacillus coagulans spore inactivation through the application of oregano essential oil and heat. LWT Food Sci. Technol. 46, 267-273. doi: 10.1016/j.lwt.2011.09.021

Hait, J. M., Cao, G., Kastanis, G., Yin, L., Pettengill, J. B., and Tallent, S. M. (2021). Evaluation of virulence determinants using whole-genome sequencing and phenotypic biofilm analysis of outbreak-linked Staphylococcus aureus Isolates. Front. Microbiol. 12:687625. doi: 10.3389/fmicb.2021.687625

Hennekinne, J. A., De Buyser, M. L., and Dragacci, S. (2012). Staphylococcus aureus and its food poisoning toxins: characterization and outbreak investigation. FEMS Microbiol. Rev. 36, 815-836. doi: 10.1111/j.1574-6976.2011.00311.x

Hua, X., Yang, Q., Zhang, W., Dong, Z., Yu, S., Schwarz, S., et al. (2018). Antibacterial activity and mechanism of action of aspidinol against multi-drugresistant methicillin-resistant Staphylococcus aureus. Front. Pharmacol. 9:619. doi: 10.3389/fphar.2018.00619

Hyldgaard, M., Mygind, T., and Meyer, R. L. (2012). Essential oils in food preservation: mode of action, synergies, and interactions with food matrix components. Front. Microbiol. 3:12. doi: 10.3389/fmicb.2012.00012

Jamali, H., Paydar, M., Radmehr, B., Ismail, S., and Dadrasnia, A. (2015). Prevalence and antimicrobial resistance of Staphylococcus aureus isolated from raw milk and dairy products. Food Control 54, 383-388. doi: 10.1016/j.foodcont.2015.02. 013

Kang, J., Jin, W., Wang, J., Sun, Y., Wu, X., and Liu, L. (2019). Antibacterial and anti-biofilm activities of peppermint essential oil against Staphylococcus aureus. LWT 101, 639-645. doi: 10.1016/j.lwt.2018.11.093

Kang, J., Liu, L., Liu, Y., and Wang, X. (2020). Ferulic acid inactivates Shigella flexneri through cell membrane destructieon, biofilm retardation, and altered gene expression. J. Agric. Food Chem. 68, 7121-7131. doi: 10.1021/acs.jafc. 0c01901

Kang, J., Liu, L., Wu, X., Sun, Y., and Liu, Z. (2018). Effect of thyme essential oil against Bacillus cereus planktonic growth and biofilm formation. Appl. Microbiol. Biotechnol. 102, 10209-10218. doi: 10.1007/s00253-018-9401-y
Kang, S., Shi, C., Chang, J., Kong, F., Li, M., Guan, B., et al. (2021). Label freebased proteomic analysis of the food spoiler Pseudomonas fluorescens response to lactobionic acid by SWATH-MS. Food Control 123:107834. doi: 10.1016/j. foodcont.2020.107834

Lambert, R. J. W., Skandamis, P. N., Coote, P. J., and Nychas, G.-J. E. (2001). A study of the minimum inhibitory concentration and mode of action of oregano essential oil, thymol and carvacrol. J. Appl. Microbiol. 91, 453-462.

Leyva-Lopez, N., Gutierrez-Grijalva, E. P., Vazquez-Olivo, G., and Heredia, J. B. (2017). Essential oils of oregano: biological activity beyond their antimicrobial properties. Molecules 22:989. doi: 10.3390/molecules22060989

Lithgow, J. K., Hayhurst, E. J., Cohen, G., Aharonowitz, Y., and Foster, S. J. (2004). Role of a cysteine synthase in Staphylococcus aureus. J. Bacteriol. 186, 1579-1590. doi: 10.1128/JB.186.6.1579-1590.2004

Lu, M., Dai, T., Murray, C. K., and Wu, M. X. (2018). Bactericidal property of oregano oil against multidrug-resistant clinical isolates. Front. Microbiol. 9:2329. doi: 10.3389/fmicb.2018.02329

Marques, J. D. L., Volcão, L. M., Funck, G. D., Kroning, I. S., da Silva, W. P., Fiorentini, ÂM., et al. (2015). Antimicrobial activity of essential oils of Origanum vulgare L. and Origanum majorana L. against Staphylococcus aureus isolated from poultry meat. Ind. Crops Prod. 77, 444-450. doi: 10.1016/j. indcrop.2015.09.013

Mehli, L., Hoel, S., Thomassen, G. M. B., Jakobsen, A. N., and Karlsen, H. (2017). The prevalence, genetic diversity and antibiotic resistance of Staphylococcus aureus in milk, whey, and cheese from artisan farm dairies. Int. Dairy J. 65, 20-27. doi: 10.1016/j.idairyj.2016.10.006

Miladi, H., Zmantar, T., Chaabouni, Y., Fedhila, K., Bakhrouf, A., Mahdouani, K., et al. (2016). Antibacterial and efflux pump inhibitors of thymol and carvacrol against food-borne pathogens. Microb. Pathog. 99, 95-100. doi: 10. 1016/j.micpath.2016.08.008

Morshedloo, M. R., Salami, S. A., Nazeri, V., Maggi, F., and Craker, L. (2018). Essential oil profile of oregano (Origanum vulgare L.) populations grown under similar soil and climate conditions. Ind. Crops Prod. 119, 183-190. doi: 10.1016/ j.indcrop.2018.03.049

Nostro, A., Blanco, A. R., Cannatelli, M. A., Enea, V., Flamini, G., Morelli, I., et al. (2004). Susceptibility of methicillin-resistant staphylococci to oregano essential oil, carvacrol and thymol. FEMS Microbiol. Lett. 230, 191-195. doi: 10.1016/s0378-1097(03)00890-5

Perez-Riverol, Y., Csordas, A., Bai, J., Bernal-Llinares, M., Hewapathirana, S., Kundu, D. J., et al. (2019). The PRIDE database and related tools and resources in 2019: improving support for quantification data. Nucleic Acids Res. 47, D442-D450. doi: 10.1093/nar/gky1106

Rao, J., Chen, B., and Mcclements, D. J. (2019). Improving the efficacy of essential oils as antimicrobials in foods: mechanisms of action. Annu. Rev. Food Sci. Technol. 10, 365-387. doi: 10.1146/annurev-food-032818-121727

Sanchez, E., Garcia, S., and Heredia, N. (2010). Extracts of Edible and Medicinal Plants Damage Membranes of Vibrio cholerae. Appl. Environ. Microbiol. 76, 6888-6894. doi: 10.1128/AEM.03052-09

Sarengaowa, Hu, W., Feng, K., Xiu, Z., Jiang, A., and Lao, Y. (2019). Tandem mass tag-based quantitative proteomic analysis reveal the inhibition mechanism of thyme essential oil against flagellum of Listeria monocytogenes. Food Res. Int. 125:108508. doi: 10.1016/j.foodres.2019.108508

Shi, C., Sun, Y., Zheng, Z., Zhang, X., Song, K., Jia, Z., et al. (2016). Antimicrobial activity of syringic acid against Cronobacter sakazakii and its effect on cell membrane. Food Chem. 197, 100-106. doi: 10.1016/j.foodchem.2015. 10.100

Tang, C., Chen, J., Zhang, L., Zhang, R., Zhang, S., Ye, S., et al. (2020). Exploring the antibacterial mechanism of essential oils by membrane permeability, apoptosis and biofilm formation combination with proteomics analysis against methicillin-resistant Staphylococcus aureus. Int. J. Med. Microbiol. 310:151435. doi: 10.1016/j.ijmm.2020.151435

Tapia-Rodriguez, M. R., Hernandez-Mendoza, A., Gonzalez-Aguilar, G. A., Martinez-Tellez, M. A., Martins, C. M., and Ayala-Zavala, J. F. (2017). Carvacrol as potential quorum sensing inhibitor of Pseudomonas aeruginosa and biofilm production on stainless steel surfaces. Food Control 75, 255-261. doi: 10.1016/j. foodcont.2016.12.014

Titouche, Y., Hakem, A., Houali, K., Meheut, T., Vingadassalon, N., Ruiz-Ripa, L., et al. (2019). Emergence of methicillin-resistant Staphylococcus aureus (MRSA) 
ST8 in raw milk and traditional dairy products in the Tizi Ouzou area of Algeria. J. Dairy Sci. 102, 6876-6884. doi: 10.3168/jds.2018-16208

Umeda, K., Ono, H. K., Wada, T., Motooka, D., Nakamura, S., Nakamura, H., et al. (2021). High production of egc2-related staphylococcal enterotoxins caused a food poisoning outbreak. Int. J. Food Microbiol. 357:109366. doi: 10.1016/j. ijfoodmicro.2021.109366

Wang, X., Tao, X., Xia, X., Yang, B., Xi, M., Meng, J., et al. (2013). Staphylococcus aureus and methicillin-resistant Staphylococcus aureus in retail raw chicken in China. Food Control 29, 103-106. doi: 10.1016/j.foodcont.2012. 06.002

Wang, Y., Hong, X., Liu, J., Zhu, J., and Chen, J. (2020). Interactions between fish isolates Pseudomonas fluorescens and Staphylococcus aureus in dual-species biofilms and sensitivity to carvacrol. Food Microbiol. 91:103506. doi: 10.1016/j. fm.2020.103506

Wu, Y., Liang, J., Rensing, K., Chou, T., and Libera, M. (2014). Extracellular Matrix Reorganization during Cryo Preparation for Scanning Electron Microscope Imaging of Staphylococcus aureus Biofilms. Cambridge: Cambridge University Press. doi: 10.1017/S143192761401277X

Yang, H., Gao, Y., Long, L., Cai, Y., Liao, J., Peng, J., et al. (2021). Antibacterial effect of Blumea balsamifera (L.) DC. essential oil against Staphylococcus aureus. Arch. Microbiol. 203, 3981-3988. doi: 10.1007/s00203-021-02384-6
Zhang, D., Gan, R. Y., Zhang, J. R., Farha, A. K., Li, H. B., Zhu, F., et al. (2020). Antivirulence properties and related mechanisms of spice essential oils: a comprehensive review. Compr. Rev. Food Sci. Food Saf. 19, 1018-1055. doi: 10.1111/1541-4337.12549

Conflict of Interest: The authors declare that the research was conducted in the absence of any commercial or financial relationships that could be construed as a potential conflict of interest.

Publisher's Note: All claims expressed in this article are solely those of the authors and do not necessarily represent those of their affiliated organizations, or those of the publisher, the editors and the reviewers. Any product that may be evaluated in this article, or claim that may be made by its manufacturer, is not guaranteed or endorsed by the publisher.

Copyright $\odot 2021$ Hao, Li and Shi. This is an open-access article distributed under the terms of the Creative Commons Attribution License (CC BY). The use, distribution or reproduction in other forums is permitted, provided the original author(s) and the copyright owner(s) are credited and that the original publication in this journal is cited, in accordance with accepted academic practice. No use, distribution or reproduction is permitted which does not comply with these terms. 